\title{
Aproximaciones a una poética de Obra total en Umbral de Juan Emar ${ }^{1}$
}

\section{Approximations to a Total Work poetics in Juan Emar's Umbral}

\author{
Malva Vásquez \\ Pontificia U. Católica de Chile \\ malmara@msn.com
}

\author{
Constanza Vargas \\ Pontificia U. Católica de Chile \\ cvargaspeirano@gmail.com
}

\section{Resumen}

Emar en Umbral, Primer Pilar, El Globo de Cristal practica una suerte de "cosmopolitismo periférico" al experimentar al máximo con diversas propuestas vanguardistas y formulaciones de la categoría de Obra Total. Recontextualiza así la Querella Antiguos y Modernos que desplegara en su labor como crítico de arte en el Diario La Nación por medio de la creación de una novela-drama que permite integrar tanto el polo de la producción artística como el de la recepción crítica. Emar, fiel a su entendimiento del "arte vivo" como "duda creadora", conforma a Umbral como "objeto de ansiedad". A nivel temático, el juego con lo apolíneo y lo dionisíaco nietzscheano le permite desplegar una poética de la ficción que implica una crítica de la noción moderna de autor.

Palabras clave: Obra Total, Juan Emar, Objeto de Ansiedad, Vanguardia-Multiperspectivismo.

\section{Abstract}

In Umbral, Primer Pilar, El Globo de Cristal Emar puts in practice a sort of "peripheral cosmopolitism" by experimenting to the maximum with diverse avant-garde proposals and formulations about the category of Total Work from an attitude of critical distance from those artistic projects. In Umbral he recontextualizes the Quarrel of the Ancients and the Moderns that he had displayed in his work as an art critic in the paper La Nación through different meta-literary strategies: for instance, the creation of a drama-novel that allows him to integrate both the poles of artistic production and of critical reception. Emar, faithful to his understanding of (modern) "living art" as "creative doubt", renders Umbral as an "object of anxiety" in diverse narratological levels, both thematic and formal. On a thematic level, playing with the Nietzschean Apollonian and the Dionysian allows him to display a poetics of fiction that involves, on a theoretical level, a critique of the modern notion of author.

Keywords: Total Work, Juan Emar, Object of Anxiety, Avant-Garde, Multiperspectivism.

1 Este artículo es parte del Proyecto Fondecyt Regular "Obra total y simultaneidad de la heterogeneidad latinoamericana en Umbral de Juan Emar", del cual la autora es Investigadora Responsable. Co-Investigador: Pablo Oyarzún. Constanza Vargas; Tesista de Magister. 
Creo que los argentinos, los sudamericanos en general, estamos en una situación análoga; podemos manejar todos los temas europeos, manejarlos sin supersticiones, con una irreverencia que puede tener, y ya tiene, consecuencias afortunadas.

Jorge Luis Borges

El epígrafe de Borges, que aquí convocamos, da cuenta de aquellos escritores latinoamericanos que la ensayista argentina Beatriz Sarlo llama "bifrontes", puesto que tal como lo muestra su caso paradigmático -Jorge Luis Borges- surgiendo éstos, de la oligarquía criolla y favorecidos por su formación europea, sitúan su escritura en "un juego entre dos orillas. [...] un escritor que fue, al mismo tiempo, cosmopolita y nacional" (Sarlo 15). Entre éstos, así llamados autores de culto, se sitúa Juan Emar, quien, al modo de Borges, practica una suerte de "cosmopolitismo periférico"2 al intentar en su obra monumental Umbral. Primer Pilar. El Globo de Cristal, experimentar al máximo con diversas propuestas vanguardistas y formulaciones de la categoría de $\mathrm{Obra} \mathrm{Total}^{3}$ de la tradición europea. Las obras de vanguardia, tal como lo señala Álvarez: "aportan aires cosmopolitas a las literaturas latinoamericanas y Jorge Schwartz ha identificado esta apertura de las fronteras culturales no sólo como pura referencia sino en términos de práctica textual. El "texto cosmópolis" de la vanguardia [...] describe su referente internacional y también lo reconstruye en la escritura de manera fragmentaria, indicial y metonímica" (75). Hecho este que conlleva, como veremos, en forma simultánea, a dialogar con algunos mitemas ${ }^{4}$ de la teoría del arte de Nietzsche, los que fueron reapropiados en Latinoamérica por la vanguardia. En este escrito, analizaremos algunos rasgos narratológicos de Umbral que permiten situar el proyecto de Obra Total emariano dentro de la crítica postestructuralista de la metafísica de la presencia, tributaria esta de la filosofía nietzstcheana. Así tenemos cómo la noción de "lo total" en Umbral se esboza, en primera instancia, desde las categorías nietzscheanas del juego entre lo apolíneo y lo dionisíaco, personificadas por los personajes Lorenzo Angol y Rosendo Paine, respectivamente. Esta es la matriz

2 Si bien Sarlo analiza el caso de Borges, sus palabras también podrían aplicarse a Emar: "En Borges, el cosmopolitismo es la condición que hace posible una estrategia para la literatura argentina [...] Desde un margen, Borges logra que su literatura dialogue de igual a igual con la occidental. Hace del margen una estética" (Sarlo 16).

3 La Gesamtkunstwerk u obra de arte total, "célebre expresión, usada probablemente por primera vez en la obra Ästhetik oder Lehre von Weltanschauung und Kunst (1827) de K.F.E. Trahndorff e inspirada en la reflexión estética del entorno romántico en que se produce la recepción de la filosofía de Schelling, fue apropiada a mediados del siglo por Richard Wagner con el fin de designar, como bien señala Adorno (1997: v. 13, 92) el "drama del futuro" en el que se reúnen elementos poéticos, musicales y mímicos". (Portales 124)

4 En este caso, la dualidad Apolo/Dionisios entendida como la conjunción de dos "unidades constitutivas del discurso mítico (mitemas) (las que) sólo adquieren significación porque están agrupadas en haces y estos haces mismos se combinan" (Barthes, 12). Otros mitemas, la dupla ser/devenir, memoria/olvido, amo/esclavo, entre otros. 
semántica que da comienzo a la narración: así es como a Lorenzo Angol se le "aparece y de modo harto extraño por un globo de cristal otro hombre que se ofrece para ser su doble, un amigo Rosendo Paine. Es como un contrato, abarcar entre dos el total". (Emar 11) De modo que el paratexto del Primer Pilar de Umbral - "el globo de cristal" viene a ser una metáfora de la creación artística- la que solicita un pacto entre esos dos impulsos artísticos de la naturaleza: lo apolíneo y lo dionisiaco ${ }^{5}$. Por otra parte, es obvia la ligazón del objeto globo de cristal con las esferas espiritistas y los fetiches decimonónicos de los simbolistas, con sus ideas de una conexión simbiótica, y por ende, "total", con lo poético, cimentado ahora como un nueva divinidad. Ya antes de Umbral, vemos la obsesión por dar con una definición satisfactoria del rol del símbolo en la constitución del hombre en el cuento Maldito Gato de Emar, en donde la experiencia del narrador se asocia a las esferas de lo total:

Desde aquel momento había algo más en el universo, una formación más, un reflejo, un espejo. Pero aquí, entiéndaseme bien, la palabra "espejo" puede inducir a error. La empleo porque allí en el embudo se reflejaba otro, el Todo. Pero no sólo se reflejaba; también se reproducía. Digamos claramente: se repetía. Era un nuevo total, idénticamente equilibrado como el gran total. Chiquito, ínfimo, raquítico, miserable... ¡Todo lo que se quiera! Pero era un total. (Emar Diez 55)

Patricio Lizama advierte que en Emar se da "la búsqueda de un nuevo fundamento que contenga los principios que en el orden real aclaren todo lo existente" (Lizama 957). El intento de Emar de reeditar la propuesta de obra total desde la periferia latinoamericana implicará, a la vez, la práctica de recontextualizar la vieja Querella entre Antiguos y Modernos que protagonizara en una primera etapa desde su tribuna periodística de las Notas de Arte en el Diario La Nación (1923-1927). En este oficio, se arriesgó a tomar la palestra como el más entusiasta difusor de lo moderno: las vanguardias artísticas, a la vez que el más feroz devaluador del canon criollista y naturalista que imperaba en la crítica artística de su tiempo. Proponemos en estas líneas que el juego metaartístico de Emar con la categoría de Obra Total en Umbral es una re-vuelta irónica al proyecto vanguardista de su narrativa anterior y su creencia en el poder transformador del arte. Si tuviéramos que inscribir este magno proyecto en la trayectoria de Emar y dar cuenta de su posicionamiento en el campo cultural nacional, tendríamos que hablar, grosso modo, de una tercera etapa en su producción escritural, la que tiene como vuelco existencial la automarginación del autor de la esfera pública a partir del año 1937. Con ello Emar, en un ademán similar al del escritor trasandino

5 Tesis desplegada en El nacimiento de la tragedia escrito entre 1871 y 1872 y en sus escritos póstumos. En esta su primera obra, no sólo expone de forma sistemática su estudio sobre los griegos, sino que también empieza a moldear su filosofía, influenciada por los pensamientos de Schopenhauer y por la música de Richard Wagner. Este texto trata del nacimiento de la tragedia ática, de los motivos estéticos que la inspiraron y de las causas de su desaparición. 
Macedonio Fernández ${ }^{6}$, con el cual tiene afinidades electivas notables, retira su posterior obra de la circulación hasta que llega el momento de su publicación póstuma en 1996 a cargo de Pedro Lastra y Pablo Brodsky.

En una primera etapa de su trayectoria como sujeto letrado, Emar intenta difundir las nuevas tendencias vanguardistas en sus Notas de Arte del Diario La Nación (1923-27). Posteriormente, a raíz de la clausura de este medio y a la poca repercusión crítica de dicha tentativa se suma, en una segunda fase, la casi nula recepción de sus obras narrativas publicadas el año 1934: Diez, Miltín 1934, Ayer. Después de estas fallidas tentativas, Emar se retira a partir de 1937 al campo a escribir Umbral, primero, en el fundo "La Marquesa" de Leyda y luego, en el sur de Chile (cerca de Osorno). En esta obra híbrida de seis tomos es donde construye una especie de novela (auto) biográfica en la cual realiza una peculiar amalgama entre crítica artística y ficción literaria, sus dos pasiones endémicas. En el marco de este bosquejo de periodización, situamos a Umbral en una tercera etapa del itinerario emariano, en la cual advertimos un cambio de tono o más bien una relación de "doble vínculo" respecto de las propuestas vanguardistas teatrales y pictóricas, ya que éstas, ahora, se tensionan al máximo revelando las paradojas y aporías de tales proyectos estéticos. La ambigüedad se refleja en Umbral en la tensión que se da entre la actitud paródica que carnavaliza tanto el concepto como el debate epocal en torno al proyecto estético-institucional de Obra Total -El caso Wagner - y la propia práctica de experimentación artística de Emar en torno a esta categoría, la que arroja inéditos e inestimables aportes a la que Paz llama "tradición de la ruptura" propia de las vanguardias

\section{Obra total y objeto de ansiedad}

La Querella Antiguos y Modernos que en la narrativa anterior a Umbral se nutre, fundamentalmente, de las propuestas vanguardistas literarias y pictóricas de la tradición francesa-Ayer, Un Año, Miltín 1934, Diez-adquiere una inflexión mayor en El Primer Pilar, pues al integrar un diálogo con la propuesta de Obra Total, complejiza en forma

6 Emar hará suyo también el culto a la ineditez tan vitoreado por Macedonio en sus escritos. De hecho, en 1964, a tan solo cuatro años de su muerte, el escritor escribe: "No pienso publicar hasta después de haberme ido de aquí [...] el mundo literario es una porquería peor que la de los peores glotones [...]”. (Cit. en Alvarez, 63)

7 Nietzsche cree en el proyecto wagneriano de renovación cultural y lo apoya en su planeado festival en Bayreuth, mientras Wagner confía en el talento de Nietzsche para promover su proyecto teatral de Obra Total. Sin embargo, dos años después, ambos tienen un profundo desencuentro, testimonio de lo cual es: "El texto del Nachschrifit del Caso Wagner [...] cuando luego de señalar la arrogancia y el diletantismo de Wagner y sus seguidores declara "...y lo peor: la teatrocracia-, el desvarío de la creencia en la preeminencia del teatro, en el derecho del teatro a detentar la soberanía sobre las artes, sobre el arte" (KSA 6, 42). La inminente consecuencia política de este poder estético [...]: "el teatro es una forma de la demolatría en asuntos de gusto, el teatro es una sublevación de las masas, un plebiscito contra el buen gusto..." (KSA 6, 42). De esta manera, Nietzsche parece adivinar lo que será la proyección de la industria cultural y su adulación de las masas, especialmente en lo que atañe al wagnerismo del siglo XX [...]". (Portales 123) 
hiperbólica las instancias narratológicas tanto formales como temáticas. De partida, obliga a buscar una estrategia para integrar el teatro a la narrativa ya que, como sabemos, la noción de Obra Total, desde su origen wagneriano, es una propuesta para el drama operático que se centra en la búsqueda de la integración de las artes, con el efecto de crear una experiencia multisensorial que con-funda las esferas arte/vida. Se piensa así que el espacio escénico es el lugar de mayor y más completa ilusión de verosimilitud $^{8}$, pues para Wagner el teatro es el lugar idóneo para la elevación espiritual del espectador. La categoría estética de obra total, bajo el concepto wagneriano de la Gesamtkunstwerk, integra todos los géneros artísticos, intentando afectar todo el campo sensorial del hombre y generar con ello una "renovación espiritual”. Emar va a resignificar muchos de los aportes que provienen principalmente de los lenguajes plásticos (Cubismo, expresionismo, dadaísmo, surrealismo) y de la representación teatral de corte experimental (Artaud, Pirandello, Calderón) para articularlos en una propuesta narrativa inédita de obra de arte total. Empresa titánica que, valiéndose de la hibridez genérica, construye un artefacto que en muchos pasajes se acerca a una suerte de "novela-drama" deviniendo con ello Umbral, como veremos en este escrito, en diferentes niveles narratológicos en un "objeto de ansiedad"9.

Diversas aproximaciones teóricas y lenguajes artísticos han intentado una elaboración de obra o texto total: desde el simbolismo, pasando por las vanguardias europeas y su apropiación por las latinoamericanas hasta consideraciones más contemporáneas. Desde la literatura, la tradición simbolista ha propuesto la noción y práctica de un "texto total o absoluto" (Mallarmé, Baudelaire). Por su parte, en las vanguardias se exacerba la necesidad de con-fundir arte y vida, valiéndose de dispositivos como el injerto, el collage y el montaje, los que vienen a hacer de la simultaneidad el nuevo sensorium de una modernidad tecnocratizada y capitalista. Otra modalidad de obra total se da en la tradición fantástica argentina (Macedonio Fernández, Jorge Luís Borges), materializándose en el “Texto infinito" vinculado a una estética de lo fantástico que se acerca al concepto de "obra en movimiento" u obra abierta de Eco. Es decir, un texto que se está reescribiendo indefinidamente, que es infinitamente variable (El libro de arena, Las ruinas circulares, entre otros). En el ámbito nacional, la noción de texto absoluto la retoma en poesía la propuesta vanguardista del Creacionismo de Vicente Huidobro en su manifiesto Total. En la antipoesía de Parra, por su parte, se daría en el artefacto-poema "Yo me sé tres poemas de memoria"10 (Carrasco 1985).

8 Para Aristóteles, la obra dramática y, en particular, la tragedia, es el género mimético por excelencia, ya que en este no hay mediación de un narrador como en la épica sino que nos encontramos con actores actuando, siendo así mímesis pura.

9 El término "objeto de ansiedad" es usado por primera vez por Harold Rosenberg en 1965 y es retomado por Suzi Gablick en 1987.

10 En el ámbito nacional se ha hablado al respecto de "novela total" (Goic). Iván Carrasco, por su parte, se ha encargado de reflexionar y desplegar una cartografía de la categoría de texto total desde el simbolismo hasta sus formulaciones latinoamericanas. 
En este sentido, el crítico norteamericano Harold Rosenberg llama en 1967 «anxious object» u objeto de ansiedad a ciertos objetos artísticos que provocan más interrogantes que certezas y que nos hacen dudar en tanto espectadores de si estamos ante una auténtica obra de arte: "La ansiedad del arte es un tipo peculiar de visión. Esta acaece no como un reflejo de la condición del artista, sino de su reflexión sobre el rol del arte entre otras actividades humanas. Donde la ansiedad esté ausente, nada que suceda al artista como una persona, ni siquiera la amenaza de su extinción física, desembocará en existencia, en vida" (19). El clásico ejemplo de objeto de ansiedad data de 1917, en plena eclosión de las vanguardias históricas, cuando Marcel Duchamp envió a la Exposición de la Sociedad de Artistas Independientes de Nueva York un urinario de porcelana titulado Fuente y firmado con seudónimo. Cuando su obra fue rechazada, Duchamp -jurado de esa muestra- renunció. Sin lugar a dudas, un objeto de ansiedad, con su intención desmitificadora de las bellas artes o del malentendido "arte sublime"11, de manera inevitable, trastorna y desconcierta, perturbando las creencias de la burguesía sobre la obra maestra legitimada por la tradición, el gusto y el museo. En un pasaje de su excelente estudio Itinerarios de la modernidad, Casullo desentraña los presupuestos vitales de la vanguardia, ésta sabe:

Por un lado, que está viviendo una época de tránsito, una época donde algo se está cayendo - un mundo a partir de la Primera Guerra. Un mundo terminó y algo tiene que venir. Que hay una crisis extensa. La crisis no es solamente lo que se cae; la crisis es una refecundación de las cosas. [...] La crisis plantea que desde allí se emerge como un tiempo nuevo. [...] Lo que fracasó es el hombre burgués: se necesita un hombre nuevo (87).

Subercaseaux coincide en afirmar que estas prácticas de la vanguardia esbozan la "categoría espiritual" de lo antiburgués, categoría que en la narrativa de Emar anterior a Umbral tiene su máxima expresión en la figura del artista Martín Quilpué quien con su sola presencia provoca una ruptura tanto de los órdenes naturales como institucionales (de la misma escritura de la novela). Por su parte, Nelson Osorio describe acertadamente las vanguardias como cierta "comunidad en la actitud cuestionadora" que, sin embargo, no encuentra "coincidencia en las respuestas, que son variadas, multifacéticas y hasta contradictorias" (XXIX) Siguiendo con este planteamiento de Osorio, proponemos que el objeto de ansiedad como práctica artística vanguardista se inscribiría dentro de lo que Emar llama la "duda creadora", categoría similar a la de "comunidad en la actitud cuestionadora", ya que frente a la "tradición de la forma", esto es, a la repetición de lo ya conocido, él opone la "tradición del espíritu" la que exige la búsqueda permanente de nuevas problemáticas o interrogantes artísticas: "a la primera, la he llamado muerta; a la segunda, viva". ("Algo sobre pintura moderna.

11 Para un análisis de lo sublime hecho cliché, véase Vásquez, Malva 2010. 
Ingres-Cézanne", Notas 51). Este carácter fuertemente metaartístico del objeto de ansiedad nos lleva a la conclusión de que "el proceso estético es aquel que perturba, irrita, suspende o niega los intentos de identificación o de determinación es un lugar común de la teoría del arte. [...] La experiencia estética no niega las identificaciones de su objeto oponiendo otras sino reproduciendo el proceso de su formación de manera tal que este ya no se consuma en ningún resultado" (Menke 45). Este tipo de arte "hipertélico"; esto es, el que va más allá de sus fines, es el que va a permitir bautizar a las vanguardias dentro de lo que Paz llama "la tradición de la ruptura", movimiento que extrema la búsqueda de lo nuevo y que lleva a este movimiento a firmar, según este ensayista, su acta de defunción ${ }^{12}$. De modo que si las propuestas vanguardistas (Huidobro, Arp y Emar) surgen para espantar al burgués, como refiere Galindo, su carácter fuertemente metaficcional, de búsqueda de novedad, arriesga la etiqueta de non sense o absurdo: "Por medio de la saturación informativa y de una retórica paródica establecen una suerte de paradoja receptiva, en tanto el lector no puede procesar adecuadamente la información por exceso o por falta de sistemas taxonómicos adecuados" (Galindo, Relatos como 'objetos de ansiedad'... web).

Por otra parte, la Obra Total, para Wagner, debe generarse a partir de un esfuerzo comunitario ${ }^{13}$, por medio de la cooperación entre artistas, alejándose de la idea de un artista-individuo. Nuevo desafío para Emar, quien en sus obras anteriores a Umbral siempre oponía un protagonista central que representaba los valores de un individuo-artista a la sociedad burguesa (en algunos casos, como en El pájaro verde se trata de una comunidad de amigos). Esta relación binaria se complejiza en Umbral dando paso a una relación fluídica entre las diversas instancias, rompiéndose con el binarismo estanco entre las figuras de narrador-protagonista, autor-obra, noveladrama, autor-público, etc. De ahí que lo que era un imperativo para las propuestas vanguardistas y, entre ellas, la del proyecto musical wagneriano de Obra Total -la utopía de confundir arte y vida- que en la narrativa anterior emariana se valía de la puesta en escena del artista individualista, transgresor de los órdenes institucionales ${ }^{14}$, ahora se la relativiza desde una óptica del distanciamiento irónico del narrador Onofre Borneo, el cual se configura como una suerte de antihéroe, esto es, de un hombre sin

12 Por otra parte, los proyectos vanguardistas producen un tipo de arte que requiere de un receptor activo, lo que extrapolado al caso de la narrativa emariana de Obra Total demanda una suerte de "lector modelo" (Eco), dado su carácter fuertemente autorreflexivo. De ahí que si el efecto de desautomatización perceptiva o extrañamiento (Schlovsky) fue, en su primer momento, más fácil de lograr en las artes plásticas o en las performance, en la narrativa corre el peligro de transformarse en un juego autista y/o elitista.

13 Pöltner refiriéndose al programa estético de Wagner, comenta que para él: "[... las artes aisladas siempre se dirigen sólo a la imaginación del hombre (IV/2) y lo dejan en la actitud del contemplador. En sus reflexiones sobre la necesidad y la posibilidad de la obra de arte total, Wagner describe el presente como una sociedad de individuos concretos aislados y el estado como una máquina coercitiva que destruye la libertad. La expresión de esta situación general, es decir, de la pérdida de la identidad social, es la fragmentación del arte en géneros artísticos aislados entre sí, así como el aislamiento del artista respecto del público, la necesidad de, en vez de poder crear desde la comunidad, tener primero que construirse como comunidad"(174).

14 Recuérdese al respecto, la figura de Martín Quilpué en Miltín 1934; al protagonista de Ayer, al mismo Emar ficcionalizado en El pájaro verde, entre otros. 
atributos. Así tenemos cómo la primera instancia narratológica que se constituye en un objeto de ansiedad para el lector se da en el polo artístico. Su narrador Borneo nos presenta su proyecto de autor bajo el motivo de la novela/biografía por hacerse.

\section{El retorno de la tragedia en el fundo de Curihue}

En Umbral, novela que cuenta hasta la actualidad con exiguos estudios ${ }^{15}$, Emar intenta crear una Obra total para fusionar sus dos afanes artísticos; el de crítico de arte y el de novelista. Se sirve además para ello de un juego intertextual con la teoría del arte de Nietzsche, cuya matriz se basa en "la intuición de que el desarrollo del arte está ligado a la duplicidad de lo apolíneo y de lo dionisiaco" (60). Como sabemos la obra total, para Wagner, debe generarse a partir de un esfuerzo comunitario, por medio de la cooperación entre artistas, alejándose de la idea de un artista-individuo. Wagner se basa en la tragedia griega para su idea de comunidad, esto es, de la participación entre representación y público. A fin de lograr esta participación, en Umbral se ficcionalizan los dos polos de la obra artística (Iser) o, lo que siguiendo el planteamiento de Nietzsche, corresponde a la dialéctica entre los dos instintos artísticos de la Naturaleza; el de lo apolíneo que equivale al polo artístico y el de lo dionisíaco, el polo estético de la recepción, los que aparecen representados como los estados del sueño transfigurador y de la embriaguez o éxtasis ${ }^{16}$, respectivamente. En Umbral se parte representando el polo artístico bajo la figura de su narrador-biógrafo Onofre Borneo, quien se plantea la construcción de la novela. Por otra parte, para integrar el polo estético, se nos narra la asistencia de los personajes a tertulias literarias y a representaciones teatrales, entregándosenos la recepción crítica por parte de ellos de los espectáculos presenciados. Por ello, mediante la asistencia a espectáculos teatrales con que el Capitán Angol agasaja a sus invitados en su teatro del fundo de Curihue, se posibilita mostrar cómo se da la interacción y diálogo entre los polos artístico -el de los creadores de la obra- y el estético -los espectadores o público de la misma- esto es, darle el carácter de acto comunitario al arte.

Las tres obras teatrales a que asisten los personajes en orden de sucesión en Umbral son Pacto, Blenda y Fedelspato, y El drama de Fideicomiso, siendo las dos últimas de autoría del personaje el Chino $\mathrm{Fa}$, quien también asiste a las puestas en

15 Existen escasos estudios sobre Umbral de Juan Emar. Además, ninguno de ellos intenta una lectura integral de esta novela, sino que abordan aspectos específicos, tales como el rol del artista (Labraña 2010) o el uso de estrategias metafictivas aisladas como la metalepsis (Carrasco 1981).

16 "En dos estados, en efecto, alcanza el ser humano la delicia de la existencia, en el sueño y en la embriaguez. La bella apariencia del mundo onírico, en el que cada hombre es artista completo, es la madre de todo arte figurativo [...] mientras que el sueño es el juego del ser humano individual con lo real, el arte del escultor [...] El arte dionisíaco, en cambio, descansa en el juego con la embriaguez, con el éxtasis. [...] En ambos estados el principium individuationis (principio de individuación) queda roto, lo subjetivo desaparece totalmente ante la eruptiva violencia de lo general-humano, más aún, de lo universal-natural." (Nietzsche 230-232) 
escena. Dos de ellas tienen lugar en el teatro del fundo de Curihue del Capitán Angol, funcionando este espacio regional del campo chileno como cronotopo pre-moderno, que permite privatizar la experiencia artística-cultural, desinstitucionalizarla y con ello llevarla al terreno de una comunidad de amigos, comunidad que integra a la gente del pueblo de Curihue en El drama de Fideicomiso. Así, de un modo similar a como Bajtin caracteriza el castillo como cronotopo del espacio del señor feudal, a este espacio aristocratizante de la clase oligárquica terrateniente chilena, la cual va perdiendo fuertemente su hegemonía política alrededor de la década del veinte en Chile $^{17}$, se lo mitifica en Umbral como espacio de la abundancia que permite llevar una vida de ocio creador, de tertulias literarias y veladas teatrales en las que no faltan los sofisticados festines como modo de agasajar a los amigos y contertulios. De este modo, Emar margina del espacio de la modernidad su obra, la retira de los vaivenes de la industria cultural y del mercado, emplazándola en un pasado de vida aristocrática en una cultura agraria, reeditando a su modo los tipos de sociabilidad del Chile de principios de siglo.

Por otra parte, la integración del ámbito de la recepción teatral le permite ficcionalizar en la novela algunos debates artísticos del campo cultural chileno ya planteados en la labor de difusión periodística de Emar en sus Notas de Arte. Esta polémica, conformada por dos sectores antagónicos, contextualiza la Querella Antiguos $y$ Modernos $^{18}$ en el Chile de la época y tendrá su espacio privilegiado en el cronotopo teatral del fundo de Curihue del Capitán Angol, a cuyas representaciones teatrales asisten tanto amigos como portavoces de estas dos tendencias críticas. Por medio de esta comunidad que se teje y funda en la diversidad de autores, anfitriones y público se muestra la pugna entre la crítica oficial y la defensa y/o emergencia de la vanguardia pictórico/literaria en el ámbito nacional. Es decir, entre el tradicionalismo o la "metafísica de la tradición" (Jauss) que encarna la crítica oficial y lo que Emar llamará "El Arte Vivo" en sus Notas de Arte.

\section{El sujeto como constructor ficcional}

En este apartado, analizaremos algunos rasgos narratológicos de Umbral que permiten situar el proyecto de obra total emariano dentro de la crítica postestructuralista de la metafísica de la presencia que es tributaria de la filosofía niezstcheana. Así tenemos

17 Coincidimos con Álvarez en que Emar: "vive de modo ambivalente el comienzo del siglo XX chileno, esto es, el inicio del proyecto político de las clases medias y la emergencia del proletariado en el escenario chileno: en tanto agente modernizador, manifiesta cierta identificación con ese proceso (especialmente...en la crítica a la burguesía), pero al mismo tiempo experimenta un cierto distanciamiento que proviene de la radical individualidad de sus búsquedas estéticas y espirituales" (61). Es un hecho sintomático, al respecto, que el contexto de producción de la obra (retiro de Emar en el fundo) y el de gran parte de la diégesis coincidan en sus características de espacio regional de la clase oligárquica chilena.

18 Véase Vásquez y Vargas La Querella Antiguos y Modernos , 2013 
cómo la primera instancia narratológica que se constituye en un objeto de ansiedad para el lector se da en el polo artístico. Su narrador Borneo nos presenta su proyecto de autor bajo el motivo de la novela/biografía por hacerse, o más bien haciéndose en el presente de la enunciación. Lo cual instala para su autor la interrogante sobre su propia poética, esto es, la novela se despliega desde la instancia metaliteraria misma. Desde esta reflexión sobre su quehacer, Borneo anticipa que más que narrar hechos o encontrar respuestas, en su escritura le interesa llegar a la enunciación de determinados problemas, retrotrayéndonos con ello a la concepción de "arte vivo" emariana. El primer problema, se da a través de la propia confesión de Borneo a su destinataria, su amiga Guni Pirque, sobre la decadencia de su sensibilidad vital, ya que se siente no vivir. La escritura biográfica vendría así a constituirse como el farmakon que le permitirá "intensificar su sentimiento de vivir"19, con lo cual se trae a colación, en forma implícita, la teoría fisiológica del arte de Nietzsche. La función de la escritura responde así, para Borneo -el que se confiesa como un hombre sin atributos y, por lo tanto, sin los rasgos de personaje literario- de acceder a través del desdoblamiento escritural y el perspectivismo de sus personajes a una experiencia de vida total. De manera que lo que era un imperativo para las propuestas vanguardistas y, entre ellas, la del proyecto musical wagneriano de obra total, la utopía de confundir arte y vida, ahora se la relativiza por parte del narrador, desde una óptica del distanciamiento irónico ya que se autocalifica como una suerte de antihéroe.

Ironía que Onofre Borneo duplica al decir que dedica su novela, la que comienza como narración epistolar, a su amiga Guni Pirque para que ésta "se entretenga", para lo cual decide partir por registrar las andanzas de su amigo Angol. Lo cual ya preanuncia que uno de los énfasis temáticos de su escritura está puesto en los códigos y rituales de la amistad, esto es, de un tipo de sociabilidad chilensis que se resiste a los embates de la razón pragmática de la modernidad: "Un amigo...otro amigo... había que encontrarlo. ¡Pronto un ambiente y sus condiciones! Será un ser más en mi existencia. [...] ¡Ven, amigo tranquilo! Charlemos con un aperitivo y cigarrillos, como charla todo el mundo." (Emar 29) De ahí que sea el tono conversatorio el que domina la narración y sea la lengua oral de la ciudad de Santiag, la embajadora de las anécdotas y situaciones. Angol será uno de los alter egos de Borneo, ya que como él mismo lo afirma, sus personajes le permitirán proyectar en su obra todas las posibilidades no realizadas de sí mismo, darle vida a ese mundo de fantasmas; esas "entidades semirreales" que se presentan cada vez que se quiere ser de otro modo ${ }^{20}$. De manera

19 Se hace Borneo aquí, eco de la tesis de Nietzsche - que en oposición al pesimismo romántico que encarnaría Shopenhauer, quien señala que la esencia del arte es la negación de la voluntad de vivir - de que "el arte es el gran estimulante para vivir" (14) "El arte nos recuerda estados del vigor animal; por un lado, es un exceso y derroche de una corporeidad floreciente en el mundo de las imágenes y deseos; por el otro lado, una excitación de las funciones animales por medio de imágenes y deseos de una vida exaltada, una elevación del sentimiento de vida, un estimulante de este sentimiento"(Nietzsche 34)

20 "En el fondo el fenómeno estético es sencillo; para ser poeta basta con tener la capacidad de estar viendo constantemente un juego viviente y de vivir rodeado de continuo por muchedumbres de espíritus; para ser dramaturgo 
que desde el polo artístico, se problematiza en Umbral la noción moderna de autor al mostrarse la dispersión del sujeto: Borneo se desdobla en la escritura en todos los posibles no realizados de sí mismo y por ello se despliega en la propuesta de un yo infinito. La actividad escritural de Borneo se torna así en un proceso constante de dar vida en su novela autobiográfica a un sujeto heterogéneo, cuya esencia se encuentra en transformación permanente:

$\mathrm{Al}$ salir de casa de Lorenzo me sentí profundamente solo. No había duda posible: Lorenzo se iría, emprendería su marcha, no llevando de mí más que una primera intención generadora. Y yo, mirar desde lejos lo que pudo haber sido. Yo solo, casi en desamparo. Al mismo tiempo atado, poderosamente atado a aquel ser que, a medida que se fuese alejando, mayormente me haría sentir la cuerda que nos ataba, por el hecho mismo de ir ella estirándose más y más. (Emar 28)

El proyecto emariano de problematizar la instancia de la autoría y la ficción (auto) biográfica en Umbral tiene un parangón magistral en la propuesta experimental de Macedonio Fernández de fundar una nueva novela de ruptura total con el canon del paradigma mimético. La afinidad entre la estética de Macedonio y la de Juan Emar se evidencia en una actitud similar respecto a las críticas establecidas por Nietzsche al sujeto moderno ${ }^{21}$ en La voluntad de poder, puesto que ambos escritores deconstruyen en sus respectivas propuestas narrativas la primacía otorgada en la escritura biográfica ${ }^{22}$ al yo cartesiano. Ello porque el análisis nietzscheano afirma que el sujeto no es algo dado ontológicamente, sino que su esencia reside en su proyectarse como artificio ficcional. El yo es así un constructo epistemológico o retórico, el ser es en la palabra, por lo tanto, el yo textual permanece abierto e indefinido. Según Barrenechea, los $\mathrm{Pa}$ peles de Reciénvenido de Macedonio Fernández "Movilizan la nada contra la materia, crean una nada más real y más concreta que ella, con leyes propias y con capacidad de ocupar espacio, de desenvolverse en el tiempo, de regirse por encadenamientos de causas y efectos" (Barrenechea 107-108) ${ }^{23}$.

basta con sentir el impulso de transformarse a sí mismo y de hablar por boca de otros cuerpos y otras almas." (Nietzsche 83)

21 Crítica al triunfo del monoteísmo cristiano sobre el politeísmo grecorromano que implicó el triunfo del pensamiento lógico sobre el pensamiento mítico. La tesis principal del libro establece que el arte se asienta sobre dos nociones fundamentales que los griegos de la época arcaica y clásica, es decir, los griegos previos a Sócrates, supieron mezclar con el más grande ingenio en la tragedia ática. Estas dos nociones corresponden a dos impulsos fundamentales de la naturaleza que son simbolizados por dos dioses griegos: Dionisos y Apolo.

22 Según German L. García las únicas biografías existentes y posibles en Macedonio son las huellas marcadas en la conciencia y memoria de la Otredad ya sea a través de la conversación, la acción o el texto. En el Otro, el texto biográfico carece de referente y continuamente ocurre de nuevo. Lo biográfico es libro y vida abierta. Han sido también vistas como ejercicios de paradoja que responden a la imposibilidad de contar la historia de cualquier sujeto (Sarlo cit. en Casullo 168).

23 La autobiografía de Reciénvenido se presenta como «Continuación de la nada»y, junto a personajes de Museo de la Novela de la Eterna como el Viajero o Deunamor, El no Existente Caballero nos muestra cómo el no-ser se moviliza contra la experiencia y la memoria. En opinión de Gómez de la Serna, Macedonio aspira a crear el personaje de ausencia absoluta, no ser ni nada ni nadie y desaparecer en un eterno absentismo (Fernández 30). 
Si el cuestionamiento del yo lleva en la narrativa de Macedonio a la nadificación del personaje y a constituir al mismo género autobiográfico en un "objeto de ansiedad", como vemos en la siguiente cita:

El Universo o Realidad y yo nacimos en $1^{\circ}$ de junio de 1874 y es sencillo añadir que ambos nacimientos ocurrieron cerca de aquí y en una ciudad de Buenos Aires. Hay un mundo para todo nacer, y el no nacer no tiene nada de personal, es meramente no haber mundo. Nacer y no hallarlo es imposible; no se ha visto a ningún yo que naciendo se encontrara sin mundo, por lo que creo que la Realidad que hay la traemos nosotros y no quedaría nada de ella si efectivamente muriéramos, como temen algunos (Fernández 97).

Por el contrario, en Umbral, Borneo ante la creación de su novela se siente como frente a un Umbral, límite que se sobrepasa por medio de la ficcionalización, práctica que una vez franqueado el pórtico se abre a la infinitud de lo posible: "Si la ficcionalización proporciona a la humanidad posibilidades de auto-extensión, también pone de manifiesto las limitaciones inherentes del ser humano: la propia inaccesibilidad fundamental a nosotros mismos." ${ }^{44}$ En ese desdoblamiento y refracción de todas sus posibilidades no realizadas, en ese empeño de Borneo de vivir en forma vicaria -por mediación ficcional-una experiencia total, cumplen un rol capital esos dos instintos artísticos de la naturaleza que vienen a encarnar Lorenzo Angol, el escritor apolíneo, del cual emana como su contraparte ineludible Rosendo Paine, el vividor dionisiaco: "El tendrá que vivir cuanto inconcluso hay en mí", dice Borneo. Se desprende de esto que sólo así llegaremos al "conocimiento del genio dionisíaco-apolíneo y de su obra de arte o al menos a la comprensión llena de presentimientos del misterio de esa unidad"25 (Nietzsche 61).

\section{Obra Total y puesta en abismo teatral}

La primera representación teatral que se da en Umbral es Pacto y viene a constituir una puesta en abismo del proyecto escritural de Borneo, que intenta conjugar los dos espíritus artísticos de la naturaleza: lo apolíneo y lo dionisiaco. Esta escenificación es otro guiño intertextual a la propuesta de Obra Total wagneriana. En Pacto, Lorenzo Angol y Rosendo Paine son los personajes que representan frente a sus amigos el contrato de interdependencia mutua para alcanzar la experiencia total, lo que, posteriormente, fructificará en la escenificación de una obra total en El drama de Fideicomiso. A nivel intertextual, la obra Pacto dialoga con la ópera musical Mefistófeles del compositor

24 Lo anterior, se relaciona con una visión antropológica del rol de las ficciones en la cultura, enfoque que basado en la estructura del doppelgänger muestra que sólo a través de otro de sí mismo se puede tener sí mismo. (Iser).

25 Para un desarrollo de lo demónico en la narrativa de Emar, veáse Vásquez (2012). 
Boito, quien inspirado en el Fausto de Goethe reelabora este tema tomando como personaje principal, tal como lo señala su título, a lo demónico ${ }^{26}$, esto es, al espíritu de la negación. Con lo cual vemos que se refuerza el vínculo del concepto de obra total con el de la "duda creadora" emariana, otro nombre para la aguda conciencia metaficcional, la cual, como señalábamos con anterioridad va constituyendo a Umbral como "objeto de ansiedad" continuo. En cuanto a la escenografía teatral, Pacto guarda muchas semejanzas con la puesta en escena de Mefistófeles, como podemos apreciar en la cita siguiente, por la presencia del objeto mágico que entrega el espíritu demónico a Fausto -el globo de cristal-: "En la noche del Aquelarre Satanás le ofrece una esfera de cristal como si fuera el mundo. He aquí el mundo...Arrojó al suelo de la esfera y el estallido del mundo... a lo cual la multitud responde danzando endiabladamente alrededor de un caldero" (114). Cotéjese la anterior cita de la ópera Mefistófeles de Boito con el siguiente fragmento de Pacto:

Fuera aparecen siete mujeres que, de acuerdo con el porte del tubo, tienen unos 40 centímetros de estatura. Van elegantemente ataviadas; son hermosísimas; cogidas de las manos, danzan con frenesí. Desde el globo de cristal el picaflor, golpeando, llévales el compás. Al centro del tubo, sobre la mesa, se forma un trozo de carbón. Poco a poco este carbón adquiere la silueta de un hombre -de no más de 20 centímetros de estatura- con gabán y sombrero negros. Marcha, cruza la pared de humo del tubo y sale a la mesa. Acto continuo las mujeres cesan su danza y se arrojan a puntapiés contra el hombrecito [...]. Ahora el picaflor gira enloquecido. El murciélago, con las alas abiertas, se detiene y chirrea. Lorenzo no se ha movido. Rosendo contempla abismado y sonriente (Emar 137).

Tal como Borges intentara encarnar un "Zaratustra latinoamericano" en su cuento Funes el memorioso, en Umbral también hay indicios de una parodia a la filosofía nietzscheana. Es la categoría antimetafísica del devenir, la que muestra su sentido paradojal cuando Lorenzo, el creador apolíneo, insta a Rosendo, su contraparte dionisíaca, a predicar a los demás sobre esos momentos de plenitud, de intensificación del sentimiento de vivir que experimenta en sus orgías alucinógenas y de desenfreno sexual. Rosendo contesta que él no puede predicar a los demás ni hacer ninguna obra, puesto que esto sería "salirse de los fenómenos cósmicos”, esto es, del inocente devenir. Por lo mismo, tampoco puede Rosendo recordar ${ }^{27}$, dado que como bien él lo dice: "Se recuerda lo que no se es. Y de noche yo era un nuevo hombre. No podía hacer obra alguna pues las era yo todas ellas" (Emar 157). Esto puede cotejarse con la definición de Nietzsche sobre "la esencia de lo dionisíaco", apelando a la analogía de este estado

26 Para un desarrollo de lo demónico en la narrativa de Emar, veáse Vásquez (2012)

27 Para Nietzsche, el hombre moral es el hombre capaz de hacer promesas, capaz de cumplir lo prometido, es un hombre con memoria; es la memoria la que edifica ese sujeto libre y responsable. Véase al respecto La Genealogía de la moral. 
con el de la embriaguez y la unidad ${ }^{28}$. Lorenzo Angol encarna el problema del goce extremado del pensamiento: "En el hombre cerebral o refinado, imaginar el goce que ha de venir y recordar el goce que ha pasado es una voluptuosidad infinitamente mayor que la del momento del goce mismo" (Emar 47), mientras que en Rosendo Paine se da la incapacidad de reconstruir cualquier experiencia, pues su carácter de existencia se basa sólo en el goce de los sentidos. Es en este último, en Paine en el cual se advierten las características más sobresalientes de un decadente:

ROSENDO: Yo no temo a las mujeres ni a las drogas ni a nada. [...] sin embargo, siento que nada vivo, que estoy y que sigo vegetando. Pues he de confesarte: no creo que haya sensación tan deprimente como la que sigue a un intenso momento de vida. Es el terrible "día siguiente" de todo vicioso. ¿Será acaso el contraste de tanta vivencia con la mezquina vivencia cotidiana? Si es así, el recuerdo de mi pasado vibrante y lleno de emociones es lo que hoy me ha de hacer sentir que, aunque volviera a una existencia desbordada, seguiría viendo gris y pensando que vegeto en la nada (Emar 164).

De esto se desprende que tanto el "hedor masturbatorio" del pensamiento que vuelve sobre sí, como el extremado hedonismo sujeto al devenir, derivan en una sensación de "sentirse no vivir", por lo que ambos estados -lo apolíneo y lo dionisíaco- compartirían la incompletud, la impresentabilidad de lo total. De modo que mediante esta dupla de la subjetividad artística sólo se constata la experiencia trágica del autoconocimiento, ya que este saber se sitúa en la tensión paradójica "entre liberar lo dionisíaco (usar la disolución como alquimia o transfiguración) y liberarnos sobre este vacío de fondo)". (Hopenhayn 34) Es la estética de lo discontinuo de la cosmovisión helénica, la manera que encuentra Nietzstche -y que Emar suscribe a su vez en Umbral para mostrar la dialéctica del proceso artístico- para cuestionar la razón pragmática de la modernidad. El devenir en que se alterna la fusión dionisíaca y la configuración apolínea en el que las figuraciones no perduran y, por lo tanto, no permiten la cosificación de la subjetividad ${ }^{29}$.

Por otra parte, la cita a la supuesta doctrina esotérica de Rudolf Steiner que hace Borneo va en el mismo sentido: "Y he leído - creo que en Rudolf Steiner- que "toda idea que no se convierte en ideal mata una fuerza del alma”. Y podríamos definir un ideal diciendo que es la idea que no admite aplazamiento alguno. Aquí se aplaza y se aplaza. El ideal pasa a ser idea que mata fuerzas del alma" (Emar 120). Aquí podemos

28 "Ahora, en el evangelio de la armonía universal, cada uno se siente no sólo reunido, reconciliado, fundido con su prójimo, sino uno con él, cual si el velo de Maya estuviese desgarrado y ahora sólo ondeara de un lado para otro en jirones, ante lo misterioso Uno primordial en él resuena algo sobrenatural: se siente dios [...] El ser humano no es ya un artista, se ha convertido en una obra de arte: para suprema satisfacción deleitable de lo Uno primordial, la potencia artística de la naturaleza entera se revela aquí bajo los estremecimientos de la embriaguez". (Nietzsche 44-45)

29 Estamos conscientes que esta hipótesis requiere de un desarrollo mayor en Umbral, pero este escrito intenta aportar un mapeo preliminar tanto de temáticas como de aspectos formales vinculados al concepto de obra total. 
leer la crítica nietzscheana a que nos hemos referido, en cuanto al predominio de lo racional en la cultura moderna a partir del advenimiento de la filosofía socrática, producto de lo cual se da el olvido de una de las fuentes de las cuales se nutría la tragedia antigua: el culto a lo dionisiaco. Borneo se obsesiona por una experiencia total ${ }^{30}$, experiencia que no puede tener lugar en la ciudad gris, santiaguina, sino que aflora en un recuerdo al paseo que diera al Museo de París donde se encuentra casualmente con el grupo de artistas plásticos vanguardistas: Delacroix, Tintoretto, entre otros:

Montparnasse...qué buena y querida cosa fue. Innumerables gentes...viviendo unidas y entusiastas en una sola mirada horizontal: las artes todas...pues de aquel sitio y aquella época evocaba yo una imagen global, una imagen de un solo instante, todo entero marcada por una tónica exclusiva. (...) Y era natural iiiformábamos las mil puntas erizadas de las 1.000 posibilidades de destino que abriga la humanidad!!! (142).

En este encuentro se da el sentimiento de plenitud como sentimiento de complicidad de pertenecer a una comunidad fraternal, transnacional, a una aristocracia del espíritu como potencial regenerador de la humanidad. Casullo se refiere a este sensorium de las vanguardias del modo siguiente:

esta conciencia -la de la velocidad- habilitaba [...] la idea de que la historia no solamente se aceleraba en las estructuras productivas, sino también en el campo de las ideas, de los proyectos colectivos, de los armados doctrinarios, para aparecer como posibilidad de ruptura de modelos y lógicas, y el pasaje a otro momento de la Modernidad, momento que sería claramente post-burgués. De ahí la idea [...] de la necesidad de constituirse en avanzada para este tránsito de un tiempo a otro (67).

\section{Espacio autobiográfico y palimpsesto}

La obra total se hace asimilable a sujeto total en Umbral con lo cual se deconstruye la noción de "espacio autobiográfico" al mostrarlo como género paradojal que juega a confundir realidad y ficción. El autor empírico -Juan Emar- se con-funde con el yo textual que corresponde al narrador Onofre Borneo, y éstos dos últimos con los personajes Rosendo Paine y Lorenzo Angol. Ficción y realidad se hacen así intercam-

30 La palabra "total" tiene obsesivas recurrencias en Umbral llegando a connotarse como un "fetiche fallido". Borneo nos adelanta que en el Tercer Pilar, titulado San Agustín de Tango "Parece que su voz de orden fuese "Sed cualquier cosa pero sedla en su totalidad". En la Taberna de los Descalzos "todos y todas se agitan al máximo de sus posibilidades". Para Pöltner: "La presentación real, tal como sólo es pensable en la obra de arte total, es "posible sólo mediante una proclamación a la universalidad de la receptividad artística del hombre, mediante un comunicado a su organismo sensible completo, no a su imaginación". (IV/2) [...] El hombre entero tiene que ser abarcado y en cierta manera arrebatado" (178). 
biables, lo cual se refuerza por medio del montaje del cuento El pájaro verde (1937) al interior de la novela. En este relato, la anterior búsqueda de una experiencia total, en tanto manifestación de la esencia de lo dionisíaco, alcanzará su clímax, pero a este cuento de Emar se le cambiará su protagonista central. Si anteriormente este era Juan Emar, ahora se transmuta en Rosendo Paine y esta narración enmarcada cumple la función dentro de Umbral de contarle Borneo a su amiga Guni Pirque cómo murió el tío José Pedro ${ }^{31}$. Al mismo tiempo, es la narración de una experiencia total vivida por el grupo de amigos de Borneo en la bohemia parisina. Aquí el vehículo musical en tanto lenguaje universal del sentimiento, es el tango y su letra despliega el tópico del tempus fugit, el que se conjura mediante la práctica del carpe diem de la bohemia: "Yo he visto un pájaro verde/ bañarse en agua de rosas/ y en un vaso cristalino/ un clavel que se deshoja".

Este montaje del cuento rompe, en forma abrupta, con la verosimilitud de la perspectiva narrativa, ya que si Onofre Borneo es quien, supuestamente, injerta este relato, surge la paradoja de que se nos transforma en un narrador omnisciente, pues relata la biografía del loro desde su nacimiento y descubrimiento por los exploradores científicos al Amazonas, su posterior estadía en Francia y su aterrizaje final en Santiago de Chile. No obstante esta doble ruptura del verosímil realista, esta mirada panóptica ya estaría anticipada por el intercambio de protagonistas que se da en Umbral. Juan Emar, que apareciera como personaje de su cuento El pájaro verde en 1934, se ha metamorfoseado esta vez en Rosendo Paine ${ }^{32}$.

Concluimos estas aproximaciones a la propuesta de Obra Total en Umbra, destacando la relevancia en ella de una singular concepción del tiempo. Para Emar, el artista debe realizar una transmutación temporal a fin de "lograr la sublime alquimia de tratar el pasado como porvenir" (Emar 118). Para ello, esta poética de obra total se conforma como un mecanismo dislocador de una serie de oposiciones binarias de la episteme moderna, entre ellas, como vimos la de realidad versus ficción y para los efectos de lo que nos interesa aquí, la de pasado versus futuro. Un ejemplo de esta "sublime alquimia de tratar el pasado como porvenir" en Umbral es el "devenir futuro" de todas las obras anteriores del autor, las que mediante el dispositivo vanguardista del injerto, se condensan rearticuladas y resemantizadas al interior de Umbral. Así no sólo su cuento El Pájaro Verde, como vimos anteriormente se injerta con modificaciones en Umbral, sino que todas sus narraciones -Un Año, Ayer, Diez, Miltín 1943-, además de varios escritos testimoniales e inéditos ${ }^{33}$.

31 Se nos dice que el tío Pedro pagó por no saber nada de París y sólo conocer cuatro calles santiaguinas. Se acusa a Rosendo Paine de hacerse cómplice del loro al no impedir el ataque de este al tío.

32 Es de destacar al respecto que ya anteriormente se ha relatado la afición al opio de Rosendo, lo cual nos reenvía al autor empírico. Si Lorenzo dice que "Bajo el signo del opio el tesoro es” más adelante surge la pregunta: “A base de opio haremos esta transformación humana?" (Emar 84).

33 Cavilaciones (Wallace 1993); "Una Carta" (Wallace 1997), además de los textos testimoniales "Cartas a Guni" (2011), "Mi Vida" (1997). 
Este injerto de todas sus obras anteriores a Umbral obliga a releer dicho gesto vanguardista bajo la noción de palimpsesto o texto total, en la medida en que para Emar "todos son todo. "Todos" sería el hecho de existir; "todo" sería aquel plano más alto; esa como intuición que yo tuve y que tiene y practica Palemón de Costamota, sería la posibilidad siempre presente de una comunicación entre lo que existe y el plano sin leyes" (Emar 145). Es decir, el injerto se subentiende como parte del proceso de llegar a la conformación de un texto total que no sólo juega, como hemos visto, con hacer gala de la mezcla de un sinfín de géneros - tales como la carta, el documento, la narración intercalada, la novela/drama, la biografía, la nota, el artículo de costumbres, la crítica de arte, el listado, entre otros, lo que surge del diálogo y la necesaria hibridez que se produce al entender la tradición como un organismo vivo: "Quiero dejar libre el vivir de todos, que el ignoto soplo de vida los lleve, nos lleve a uno de los mil caminos de imprevistos eternos" (Emar 130).

Es esta continua tarea de reactualización de La Querella entre Antiguos y Modernos, el modo en que Jauss entenderá la tradición de la ruptura: esto es, como una incesante búsqueda de crear en el espectador el efecto de asistir a una siempre renovada preocupación por corroborar su percepción artística mediante la confrontación de sus lecturas con las de la comunidad (Lector social e histórico) ${ }^{34}$. Es ést, el anhelo que pervive en Umbral, el que entiende que, para hablar de una "tradición viva, debe existir una comunidad interpretante que subsista en su empeño de ser parte del objeto artístico y que por ello mismo persevere en leerlo como un "objeto de ansiedad". Un ejemplo de lo cual puede advertirse en el episodio referido a la muerte de Chinchilla, muchacha con la que Lorenzo Angol habría planeado ejecutar una serie de experimentos. Aquí vemos cómo el doctor Hualañé realiza un particularísimo protocolo de autopsia, en donde lo que a simple vista podría ser tildado de absurdo -cazar el último suspiro de la mujer- es una metáfora del elán vital que jamás se pierde:

El doctor Hualañé hizo retirarse a todo el mundo del cuarto mortuorio, cerró puertas y ventanas y se lanzó a la caza de ese último suspiro. Dicen que lo encontró en parlamento con un gusanillo maderero, convenciéndolo que le permitiera escapar por el agujerito que este había taladrado en una viga del techo; que ya en el entretecho le sería fácil encontrar por donde escurrirse a la gran atmósfera que le dio vida. El doctor Hualañé lo enfrascó y lo lacró, y luego de expresarnos a todos nuestras sentidas condolencias, se alejó en su auto prometiendo a Lorenzo comunicarle el resultado de su análisis" (Emar 332).

34 "El lado productivo y el receptivo de la experiencia estética entran en una relación dialéctica: la obra no es nada sin su efecto, su efecto supone la recepción, el juicio del público condiciona, a su vez, la producción de los autores. La historia de la literatura se presenta en adelante como un proceso en que el lector, como sujeto activo, aunque colectivo, está frente al autor, que produce individualmente, por lo que ya no puede ser eludido como instancia mediadora en la historia de la literatura" (Jauss 73-74). 
En el fragmento citado, la focalización en aquel último suspiro de Chinchilla hace del relato del término de la vida un objeto de ansiedad que desacraliza la mirada tradicional de la muerte, asociada a lo solemne y al fin. En esta escena el hálit; el último suspiro que conversa con el gusanillo que es símbolo de la muerte y la descomposición, transforma la inminencia de la muerte en el mitema simbolista del elán vital en su búsqueda de confundirse con el total.

\section{Referencias}

Alvarez, Ignacio Novela y Nación en el siglo XX Chileno. Santiago: Ediciones Universidad Alberto Hurtado. 2009. Medio Impreso.

Barthes, Roland. Mitologías. México: Siglo XXI, 2008. Medio Impreso.

Barrenechea, Ana María. Textos hispanoamericanos. De Sarmiento a Sarduy. Caracas: Monte Ávila Editores, 1978. Medio Impreso.

Carrasco, Iván. "El proyecto del texto absoluto en la poesía hispanoamericana". Estudios Filológicos 20(1985) 97-108. Medio Impreso.

Casullo, Nicolás. Itinerarios de la Modernidad. Buenos Aires: Eudeba, 1999. Medio Impreso.

de Stefano, Victoria. Poesía y Modernidad, Baudelaire. Caracas: Fondo Editorial de Humanidades y Educación. 1984. Medio Impreso.

Emar, Juan. Escritos Sobre Arte. Santiago: Dirección de Bibliotecas, Archivos y Museos, 1996. Medio Impreso.

---. Umbral. Primer Pilar: El Globo de Cristal. Santiago. Dirección de Bibliotecas, Archivos y Museos. 1996. Medio Impreso.

--- Diez. Santiago: Editorial Universitaria, 1971. Medio Impreso.

Gablick, Suzi. ¿Ha muerto el arte moderno? Madrid: Hermann Blume, 1987. Medio Impreso.

Galindo, Oscar. "Relatos como 'objetos de ansiedad' en Huidobro, Arp y Emar". Documentos Lingüísticos y Literarios. 24-25 (2001-2002): 15-22. www.humanidades. uach.cl/documentos_linguisticos/document.php?id=136. Fecha de ingreso: julio de 2013. Sitio web.

González de Requena Farré, Juan Antonio. “Comunidades Interpretativas: perspectivas de la Hermenéutica Literaria de Stanley Fish”. Alpha .29 (2009) 233-249. Fecha de ingreso: 28 de julio de $2013<$ http://www.scielo.cl/scielo.php?script=sci_ arttext\&pid=S07182201 2009002900016\&lng=es\&nrm=iso $>$. Sitio web.

Hopenhayn, Martín. Después del nihilismo. De Nietzsche a Foucault. Santiago: Andrés Bello, 1997. Medio Impreso.

Iser, Wolfang. "La ficcionalización: dimensión antropológica de las ficciones”. Teorías de la ficción literaria. Madrid: Arcos, 1976. Medio Impreso. 
Lizama, Patricio. “Jean Emar/Juan Emar: la vanguardia en Chile” Revista Iberoamericana. Vol. LX, Núm. 168-169, Julio-Diciembre (1994). 945-959. http://revistaiberoamericana.pitt.edu. Fecha de ingreso: julio de 2013. Sitio web.

Menke, Cristhopher. Estética y Negatividad. Buenos Aires: F.C.E. 2001. Medio Impreso. Nietzsche, Friederich. El nacimiento de la tragedia. Buenos Aires: Alianza, 1987. Medio Impreso.

---. Fragmentos Póstumos. Vol. IV: 1885-1889. Madrid: Tecnos, 2006. Medio Impreso. Osorio, Nelson. "Para una caracterización histórica del vanguardismo literario hispanoamericano". cvc.cervantes.es/literatura/aih/pdf/12/aih_12_7_023.pdf. Sitio web.

Paz, Octavio. Los Hijos del Limo. México: Siglo XXI, 1997. Medio Impreso.

Piña, Carlos. "Ser y Tiempo en Juan Emar". Mapocho. 60 (2006). Medio Impreso.

Pöltner, Günther. "La idea de Richard Wagner de la Obra de arte total". Thémata 30 (2003): 171-185. Medio Impreso.

Portales, Gonzalo. "Nietzsche-Wagner: Preeminencia de la poesía en la obra de arte total”. Revista Estudios filológicos 49 (2012) 117-125. Medio Impreso.

Raymond, Marcel. De Baudelaire al Surrealismo. México: FCE, 1996. Medio Impreso.

Rosenberg, Harold. The Anxious Object. New York: The New American Library, 1969. Medio Impreso.

Sarlo, Beatriz. Jorge Luis Borges: un escritor entre dos orillas. Madrid: Siglo XXI, 2007. Medio Impreso.

Subercaseaux, Benjamín. Historia de las Ideas y de la Cultura en Chile. Tomo III. El Centenario y las Vanguardias. Santiago: Universitaria, 2004. Medio Impreso.

Vásquez, Malva. "Lo sublime y lo impensado en la apuesta vanguardista de Miltín 1934 de Juan Emar”. Aisthesis 50 (2011) 216-229. Medio Impreso.

---. "Imaginario demónico y apuesta vanguardista en la narrativa de Juan Emar". Anales de Literatura Chilena 18 (2012) 51-70. Medio Impreso.

Wallace, David. "Cavilaciones de Juan Emar". Universidad de Chile, 1993. Tesis de Licenciatura en Literatura.

Recibido: 14 agosto 2013

Aceptado: 08 enero 2014 